ISSN: 0213-2052 - eISSN: 2530-4100

DOI: http://dx.doi.org/10.14201/shha201836165186

\title{
EL MITO DEL AVE FÉNIX EN EL PENSAMIENTO SIMBÓLICO ROMANO
}

\section{The Myth of the Phoenix in the Roman Symbolic Thought}

\author{
Aitor FREÁN CAMPO \\ Universidad de Santiago de Compostela \\ aitor.frean.campo@gmail.com
}

Fecha de recepción: 1-11-2017; aceptación definitiva: 11-6-2018

BIBLD [0213-2052(2018)36;165-186]

RESUMEN: Se propone un análisis exhaustivo del mito del ave Fénix en el pensamiento simbólico romano y su evolución desde la tradición griega hasta su redefinición cristiana. Para ello, se prestará atención a las principales fuentes textuales, iconográficas y epigráficas de época romana documentadas hasta el día de hoy.

Palabras clave: ave Fénix; Escatología romana; Mitología romana; Paradoxografía; Religiosidad y mentalidad romana.

ABSTRACT: It is proposed an exhaustive analysis of the Phoenix myth in the Roman symbolic thought and its evolution from the Greek tradition to the Christian redefinition. For this purpose, we will study each of the main textual, iconographic and epigraphic sources of the Roman period.

Keywords: Paradoxography; Phoenix; Roman eschatology; Roman mythology; Roman religiosity and mentality. 


\section{OBjetivos y Metodología}

El ave Fénix constituye un elemento mítico que, frente a otras creaciones de la antigüedad, pervive en la sociedad del siglo xxI, aunque más como un símbolo de referencia que como un mito propiamente dicho. Así, si preguntáramos a nuestros allegados acerca de esta criatura, seguramente nos hablarían de un ave de tonos rojizos, de extraordinaria longevidad que, alcanzado el momento de su muerte, envolvería su hermoso cuerpo en llamas para renacer, a continuación, de sus propias cenizas. Es posible, incluso, que nos ilustraran sobre las capacidades curativas de sus lágrimas. Ahora bien, si planteáramos la cuestión de sus orígenes, lo más probable es que el discurso se adentrara en el ámbito de la confusión o, lo que es peor, del silencio.

A lo largo de este trabajo nos proponemos analizar y comprender la concepción que los romanos tenían de esta criatura legendaria dentro de su pensamiento simbólico. Además, trataremos de observar como esta fue evolucionando a lo largo del tiempo, como consecuencia de constituir una entidad abstracta y, por lo tanto, carente de un referente objetivo y perceptible que permitiera definir elementos tan básicos como su apariencia o su significado último.

Para ello, abordaremos más de una veintena de fuentes textuales de diversa cronología que, si bien no constituyen la totalidad de referencias al ave Fénix de la antigüedad, desde nuestro punto de vista, sí que se corresponden con las más relevantes a la hora de caracterizar el mito en época romana. Asimismo, complementaremos dichas fuentes con vestigios arqueológicos como las representaciones iconográficas contenidas en pinturas, mosaicos y piezas numismáticas o las escasas muestras epigráficas que han pervivido hasta nuestros días y que hacen alusión a la temática del Fénix.

Somos conscientes de que el análisis de este tipo de fuentes no es suficiente para alcanzar la verdadera repercusión del mito en el pensamiento simbólico romano, y menos aún del presente en cada uno de los territorios que conformarán su Imperio. Las fuentes literarias transmiten realidades que difícilmente pueden ser trasladadas más allá de las inquietudes intelectuales de las oligarquías, situadas casi siempre próximas a la metrópolis. De igual modo, la presencia del mito en ellas no siempre viene acompañada de su creencia o del intento de plasmar su vigencia en la sociedad de su tiempo, sino que, más bien, responden a ejercicios de erudición que, en el caso del Fénix, se traducen en alusiones a hechos sobrenaturales a través de los cuales se busca saciar la curiosidad humana 
o bien tratar de superar los límites de su naturaleza mortal e inferior a la de los dioses.

Algo similar sucede con las fuentes iconográficas y epigráficas. Ambas se desarrollan en contextos propios de élites sociales con los medios económicos suficientes para llevarlas a cabo y, por lo tanto, con la capacidad de acceder a unos conocimientos y a una cultura vetados para la inmensa mayoría de la sociedad. En ellas, y de manera más evidente en la numismática, su función propagandística aspira más a identificar al promotor con el símbolo del Fénix que a materializar la perduración de su mito.

Aun así, todas ellas constituyen las evidencias más directas para alcanzar nuestros objetivos. No nos permitirán comprender cómo irrumpió y evolucionó el mito del Fénix en cada uno de los habitantes de la Roma republicana e imperial, pero sí nos proporcionarán una imagen aproximada de cómo se concebía por parte de la intelectualidad de cada época y de cada contexto cultural.

Sin embargo, antes de adentrarnos en el mundo romano es imprescindible retroceder en el tiempo, observar las fuentes de las que será deudor y comprender, aunque sea de forma superficial, cuál pudo haber sido el significado originario del mito del ave Fénix.

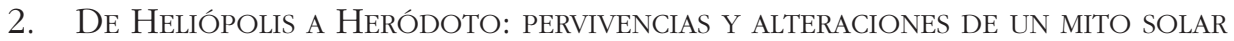

Al igual que otras muchas construcciones simbólicas originarias del mediterráneo oriental, los romanos recibieron de la tradición griega las primeras referencias del ave Fénix y, entre ellas, la más antigua de todas procedía de Hesíodo ${ }^{1}$. Este, en una exposición acerca de la longevidad que podían alcanzar diversos seres, afirmaba que el Fénix sobrevivía a 972 generaciones de hombres, aunque su existencia representaba tan solo la décima parte de lo que vivían las ninfas. Con todo, no será hasta el siglo v a. C. cuando encontremos una caracterización más definida del mito a través de Heródoto:

También hay otro pájaro sagrado cuyo nombre es Fénix. Yo no lo he visto más que en pintura, pues resulta que visita a los egipcios en contadas ocasiones: cada quinientos años, según cuentan los de Heliópolis; y aseguran que solo se presenta cuando muere su padre. Ahora bien, si es fiel reflejo de su representación pictórica, su tamaño

1. Hes. Fr. 304. Este mismo tratamiento del Fénix volverá a aparecer en el siglo IV d. C. de la mano de Ausonio (Auson. 5), quien recurrirá al ave en un ejercicio de mera erudición y de recuerdo a la obra Hesíodo. 
y contextura son como sigue. Tiene las plumas de sus alas doradas y rojas; por lo demás, se asemeja mucho a un águila por su silueta y tamaño. Y cuentan - aunque, a mi juicio, el relato es inverosímilque este pájaro lleva a cabo la siguiente proeza: partiendo de Arabia, transporta al santuario de Helios el cuerpo de su padre envuelto en mirra y lo sepulta en dicho santuario. Lo transporta del siguiente modo: primeramente da forma a un huevo de mirra todo lo grande que puede llevar y luego prueba a volar con él; una vez realizada la prueba, hace, entonces, un agujero en el huevo y mete en él a su padre, emplastando con la mirra extraída el orificio por el que, al hacer el agujero en el huevo, introdujera el cuerpo (con su padre dentro, el peso vuelve a ser el mismo) y, una vez emplastado el agujero, transporta el huevo al santuario de Helios en Egipto. Esto es lo que, según cuentan, hace ese pájaro ${ }^{2}$.

Esta información de Heródoto puede considerarse fidedigna en el sentido de que sabemos que el historiador visitó Heliópolis en persona y entabló conversación con sus sacerdotes ${ }^{3}$. Ahora bien, que el relato de Heródoto se base en testimonios directos de personas que convivían y daban sentido al mito del Fénix, no impide que el historiador de Halicarnaso introdujera ciertas alteraciones en el mismo, como resultado de una mala interpretación personal derivada de la inevitable adaptación del mito egipcio a sus parámetros culturales y simbólicos. Por otra parte, ¿qué es lo que pudo haber visto y escuchado Heródoto en Heliópolis? Seguramente nunca lo sepamos, pero resulta plausible que contemplara ciertos jeroglíficos, papiros mitológicos o grabados murales en donde se materializara una alegoría mítica que explicara el origen del templo y de los rituales y cultos que tendrían lugar en su interior. ¿Pudo, por lo tanto, haber confundido la información que estaba viendo con la que estaba escuchando?

No es este ni el momento ni el espacio para abordar los componentes de la antigua Yunu y las características de los actos que tenían lugar en ella, simplemente, basta con indicar que, junto a Menfis, Heliópolis constituyó el principal núcleo religioso de Egipto y la cuna de una cosmogonía basada en la Enéada helipolitana que tenía como protagonista al dios solar Ra-Atum-Kheprí ${ }^{4}$. En ella, los mismos sacerdotes se encargaron de confeccionar una metáfora con la que ejemplificar los hechos que

2. HDT. 2. 73. Traducción de C. Schrader (Madrid, 1977).

3. HDT. 2. 3.

4. La triple denominación no debe interpretarse como una manifestación de una divinidad de naturaleza triple o trifuncional, sino como una alusión a tres facetas distintas de un mismo dios identificado con el sol y sus diferentes estados diurnos. Así, Khepri 
quedaron registrados en documentos como los Textos de las Pirámides o la tradición recopilada en el Papiro Bremmer-Rhind en los que se describía el nacimiento del dios Ra-Atum-Khepri y, con él, el origen de todo lo conocido.

Dicha imagen, en un primer momento, consistía en un loto localizado en las inmediaciones de una montaña que, al brotar, descubriría la presencia de un niño que habría sido autogenerado. Transcurrido el tiempo, la alegoría del dios sol nacido del loto pasaría a identificarse con un ave, el Bennu, una especie de garza hoy extinta (Ardea Bennuides) que pronto sirvió como símbolo de Ra-Atum-Khepri en los Textos de las Pirámides o de su $B a$, es decir, de su fuerza anímica o espiritual, tal como se afirma en Los libros de los muertos.

Según la tradición heliopolitana, el Bennu nacía cíclicamente de una llama que brotaba del árbol sagrado de la persea (ished), un hecho extraordinario que se asoció como un símbolo de la encarnación del sol y de su constante resurrección diaria. Aunque no conocemos a ciencia cierta cada cuánto tiempo tendría lugar el nacimiento del Bennu, la opinión mayoritaria hablaba de una media de 1.460 años, el período establecido para el surgimiento de un nuevo ciclo sotíaco o gran año egipcio ${ }^{6}$.

La importancia religiosa del centro de Heliópolis y su influencia política en determinados momentos de la historia egipcia hicieron que todas estas alegorías fueran utilizadas por las distintas dinastías faraónicas para representarse como herederas del dios solar que, al igual que él, habrían sido generadas de su misma esencia. Por otro lado, esta circunstancia justificaba el hecho de que en las escrituras jeroglíficas se designara a cada faraón con la figura del Bennu seguido de su nombre.

A raíz de lo expuesto, consideramos que lo que Heródoto debió de escuchar en su visita a Heliópolis tenía que ver con el mito del nacimiento del dios solar que allí era venerado y su asociación con el Bennu que nacía cíclicamente en la misma ciudad, marcando el inicio de una nueva etapa de prosperidad. Ahora bien, las diferencias morfológicas existentes entre el Bennu y el Fénix que nos describe Heródoto nos hacen pensar que lo que vio no se correspondía con lo que escuchó o que, al menos, malinterpretó la información que estaba recibiendo con la que realmente estaba contemplando. En este sentido y, a pesar de movernos siempre en

representaba al sol naciente, $R a$ al sol localizado en su máxima altitud y Atum al sol poniente.

5. Textos de las Pirámides, 600: Tú [Atum] surgiste, con el Benben, en la Mansión del Benu, en Heliópolis. Traducción de J. A. Fernández Canosa (HaRT, 1994, p. 13).

6. Van den Broek, 1972, p. 72. 
el ámbito de la elucubración, consideramos probable que la imagen con la que Heródoto caracterizó al Fénix se correspondía, más bien, con la del propio Ra-Atum-Khepri en su variante antropomórfica, pero en la que se representaba con cabeza ornitomorfa y con un colorido próximo al que nos plantea en su texto.

En cualquier caso, lo que para nuestra investigación más importa es que los romanos recibirán de la tradición griega un mito de origen egipcio alterado en buena parte de sus componentes, especialmente, en lo relativo a su significado último y que girará en torno a tres conceptos fundamentales: la existencia de un ave única en su especie que renacería de sus propios restos mortales en un período de tiempo indefinido; que estaría vinculada con el sol, el fuego y el templo de Heliópolis, y cuyo origen, por su asociación con la mirra, debía de relacionarse con las tierras situadas más allá del mar Rojo, identificadas por Heródoto como Arabia, pero que no estaban ni mucho menos definidas, como ilustrará, por ejemplo, un siglo más tarde Heliodoro en sus Etiópicas ${ }^{7}$.

Por otra parte, la singularidad del animal, su extraordinaria capacidad de renovación, la belleza de su colorido plumaje y, en definitiva, su majestuosidad, fueron haciendo del Fénix un recurso literario atractivo para ilustrar determinados parajes idílicos o contextos extraordinarios, como se puede apreciar en Ezequiel el Trágico y su versión del Éxodo del siglo ir a. C. En ella, el símil planteado por Heródoto del águila se mantiene, pero matizando que alcanzaría el doble de su longitud y añadiendo nuevas informaciones como el cortejo de aves que acompañarían al Fénix en su peregrinar cíclico a Heliópolis, realidad que justificaría la visión del mismo por parte de Moisés en su salida de Egipto. Además, aunque se conservan las tonalidades áureas y rojizas que caracterizarían a su plumaje, la morfología del animal pronto se empieza a enriquecer con otras pigmentaciones. Entre ellas destacarán las purpúreas, algo que, como veremos, constituirá una constante entre los autores romanos y que, por otro lado, servirá para mantener la denominación como Fénix del animal, al derivar del griego $\Phi_{0 i v v} \xi$, es decir, aquello que se caracteriza por poseer una apariencia rojiza o purpúrea y, por lo tanto, propia de tierras fenicias.

7. HeL. 6. 3. 3.

8. Ez. Ex. 253-269. 
3. El ave FéniX en el Pensamiento Simbólico romano: Siglos i-V D. C.

Dentro del ámbito cultural estrictamente romano, no será hasta el siglo I d. C. cuando las referencias al ave Fénix comiencen a irrumpir de manera importante en los escritos de naturaleza, fundamentalmente, literaria, geográfica y naturalista. De entre ellos, tal vez, el testimonio de Plinio9 resulte ser el más destacado. En él se introducen muchas novedades con respecto al texto de Heródoto que se mantendrán, a grandes rasgos, a lo largo del Imperio romano. Así, parece ser conocedor del significado simbólico que se esconde detrás del mito al afirmar que se trata de un ave consagrada al Sol. A pesar de indicar que dicha consagración tiene lugar en Arabia y que sigue la tradición griega de la peregrinación del Fénix con los restos mortales de los que procede desde estas tierras hasta Heliópolis; Plinio señala la existencia de un altar en esta ciudad destinado a albergar sus restos mortales y la coincidencia de su nacimiento con el Gran Año en relación con el cumplimiento del ciclo sotíaco que él sitúa en 540 años. Además, en otro fragmento ${ }^{10}$, introduce una noticia oscura y de difícil interpretación acerca de un árbol que renace junto al Fénix y que, tal vez, aluda a la tradición del Bennu que se crea tras una combustión que tiene lugar en el árbol sagrado ished.

Otra novedad tiene que ver con la caracterización de la mortaja del Fénix muerto, ya que la mirra de la tradición griega parece ser sustituida en Plinio por la canela, el incienso y otras especies aromáticas que no define en un reflejo, quizás, del cambio producido en las redes comerciales de la época u otros motivos que comentaremos más adelante en relación con la generalización de la incineración como principal ritual funerario en la Roma del siglo i d. C. Por otra parte, el huevo del que hablaba Heródoto es sustituido directamente por el nido en su conjunto en un intento, tal vez, de dotar de mayor verosimilitud al relato.

En cuanto a la apariencia física del ave, si bien es cierto que la analogía con el águila se mantiene, el colorido que comenzaba a despuntarse en época helenística se consolida en el Imperio romano con un Fénix que complementa sus colores dorados y rojizos con otros rosáceos y azulados y que Plinio localiza con precisión: el color oro en el cuello, el púrpura en el cuerpo y las tonalidades rosáceas en las plumas próximas a su cola azulada. Asimismo, complementa la descripción morfológica del ave indicando la existencia de crestas en su garganta y de un copete de plumas en la

9. PLIN. Nat. 10. 2. 3-5.

10. PLIN. Nat. 13. 9. 42 
cabeza que, de nuevo, recuerda a esa ardea bennuides que se encuentra detrás del mítico Bennu egipcio.

Pero, sin duda, la principal novedad que incorpora Plinio al análisis del Fénix radica en que explica, por primera vez, qué es lo que realmente sucede entre la muerte del viejo animal y el resurgimiento del nuevo ser, una realidad que en Heródoto se omitía: de sus restos mortales, en concreto de sus huesos y médulas, nacería una larva que, posteriormente, se transformaría en un polluelo y que, al crecer, se convertiría en la radiante y esplendorosa ave.

Como no podía ser de otra manera, la noción de metamorfosis que se esconde detrás de la muerte y resurrección del Fénix no pasó desapercibida en un Ovidio que, entre otras alusiones contenidas en su amplio repertorio bibliográfico, legaba la siguiente caracterización:

[...] hay un pájaro que se rehace y reengendra a sí mismo: los asirios lo llaman Fénix; no vive de granos ni de hierbas, sino de lágrimas de incienso y de jugo de amomo. Cuando este animal ha cumplido cinco siglos de edad, en lo alto de las ramas de una encina o de la copa de una palmera temblorosa se construye un nido con las uñas y con el limpio pico, y cuando lo ha pavimentado con casia y con espigas de suave nardo, así como con trozos de cínamo y amarilla mirra, se coloca encima y acaba su vida entre perfumes. A continuación dicen que del cuerpo de su padre renace un pequeño Fénix que está destinado a vivir otros tantos años; cuando la edad le ha dado fuerzas y es capaz de llevar una carga, libera del peso del nido las ramas del elevado árbol y lleva piadoso lo que es a la vez su cuna y el sepulcro de su padre, y después de alcanzar, a través de los aires ingrávidos, la ciudad de Hiperíon [Heliópolis] lo deposita delante de la sagrada puerta en el templo de Hiperíon ${ }^{11}$.

La versión de Ovidio, realizada con anterioridad a la de Plinio, sintoniza bastante bien con la de este último, exceptuando esa vuelta a los 500 años de vida que señalaba Heródoto. Sin embargo, Ovidio introducirá también nuevos elementos que serán importantes para comprender la evolución del mismo dentro de la mentalidad romana. Así, por fin conocemos otro elemento que había permanecido en silencio hasta el momento, como es la naturaleza del alimento del Fénix: lágrimas de incienso y jugo de amomo. Su alusión entra de lleno con otra noticia que tiene que ver con la composición de lo que será la mortaja de sus restos mortales y que el relato de Plinio trataba de una manera más sucinta: se insiste en el empleo de la canela a través de la casia y se añade el nardo y el cínamo.

11. Ov. Met. 15. 391-408. Traducción de A. Ruiz de Elvira (Madrid, 1999). 
Todas estas substancias es muy posible que formaran parte de los rituales crematorios de los ciudadanos romanos más destacados de su tiempo y, con su vinculación al Fénix, Ovidio comienza a asociar su mito a la propia existencia humana, un aspecto remarcado por la purificación que realiza el animal de sus uñas y su pico con anterioridad a construir el nido que actuará, poco después, como su propio sepulcro.

Otra obra destacada de esta primera centuria, pero de naturaleza eminentemente geográfica, es la de Pomponio Mela ${ }^{12}$. En ella, se relata una versión muy similar a la de Ovidio con el objetivo de caracterizar a la Arabia originaria del Fénix y la riqueza de especies animales y vegetales que habitarían en sus exóticas tierras.

A partir de estos elementos definitorios del mito y tal como afirmábamos con anterioridad, el Fénix sirvió también como recurso literario para muchos poetas que lo emplearon como referente geográfico ${ }^{13}$, como alegoría del buen olor ${ }^{14}$, como símbolo de longevidad ${ }^{15}$ o como alusión a un elemento único, tal como hace Lucano $^{16}$ en lo que constituye la primera referencia directa a las cenizas que se originarían tras la muerte y la combustión del ave. Sin embargo, la metáfora que mayor proyección alcanzará del Fénix será la derivada de su idea de regeneración, una noción que será utilizada para complementar la idea de la Roma Aeterna y su continua renovación a través de cada nuevo emperador. Esta concepción aparece ya en este siglo I d. C. de la mano de Marcial ${ }^{17}$ en una referencia en la que, por cierto, se prolonga la vida del Fénix hasta los 1.000 años.

En cuanto a los registros arqueológicos o artísticos que nos remiten a una materialidad del mito del Fénix en la cultura popular romana de este siglo I d. C., tan solo contamos con un grabado conservado en la villa romana de Euxinus, en Pompeya. Sobre una inscripción que versa phoenix felix et $t u^{18}$ se representa a un Fénix rodeado de otras aves. La caracterización del mismo recuerda a la de un faisán y lo que distinguiría la singularidad del ave del resto sería tan solo el dorado de su plumaje combinado con tonos rojizos. De este modo, al menos en esta solitaria representación, la figuración del Fénix parece sintonizar más con la tradición griega legada por Heródoto que con la presente en los intelectuales romanos de su tiempo.

12. Mela 3. 8. 83-84.

13. STAT. Silv. 3. 2. 114

14. MART. 6. 55.

15. STAT. Silv. 2. 4. 32-37.

16. LuC. 6. 680.

17. MART. 5. 7. 1-2.

18. CIL IV, 9850. 
La información derivada de estas fuentes del siglo I d. C. resulta fundamental ya que en su mayor parte se mantendrá vigente en las posteriores, tanto en las injeridas en la tradición romana como en las relacionadas con el incipiente cristianismo. En relación a este último, Clemente en su primera Epistola a los Corintios realizada en los últimos años del siglo I d. C. redactará de la siguiente forma lo que constituye la primera referencia documentada al mito del Fénix en la tradición cristiana y en la que se puede apreciar buena parte de las características esgrimidas por Plinio y Ovidio:

Veamos el extraordinario signo que se da en las tierras de oriente, es decir, en los alrededores de Arabia. Pues existe un pájaro que recibe el nombre de Fénix. Siendo el único de la especie, vive quinientos años, pero llegado el momento de la destrucción de la muerte se hace un nido de incienso, mirra y restantes aromas en el que se introduce al cumplirse el tiempo, y muere. Al corromperse su carne nace un gusano, el cual, alimentándose de la humedad del animal muerto, se transforma en alado. Después, hecho fuerte, coge el nido en que se hallan los huesos de su antecesor y levantándolos realiza un viaje desde la tierra de Arabia hasta Egipto, a la llamada Heliópolis. De día, cuando todos lo ven, después de precipitarse sobre el altar del sol, los coloca allí y entonces emprende el regreso. Los sacerdotes examinan los registros de los tiempos y encuentran que ha venido al cumplirse los quinientos años ${ }^{19}$.

Entrados en el siglo II d. C., Tácito ${ }^{20}$ se presenta como la fuente más destacable. Su testimonio parece basarse en un estudio amplio y documentado de todo lo escrito por sus predecesores. En él se vuelve a indicar la naturaleza solar del ave y su consagración al Sol, se recupera esa tradición helenística según la cual el Fénix, en su peregrinaje a Heliópolis, sería acompañado de un amplio séquito de aves y, pese a que reconoce que la opinión mayoritaria en cuanto a su duración vital es de unos 500 años, apunta una nueva opción de 1.461 años en relación, tal vez, a la duración aproximada del ciclo sotíaco egipcio.

Si volvemos al ámbito literario desarrollado en este siglo II d. C., a las metáforas empleadas en la centuria anterior, debemos añadir su empleo como recurso para ejemplificar lo fabuloso o lo irreal, presente en el siempre escéptico Luciano ${ }^{21}$ o para señalar aquello que es único y sin-

19. Clem. Ep. Cor. 25. Traducción de J. J. Ayán Calvo (Madrid, 1994).

20. TAC. Ann. 6. 28.

21. LuCI. Nav. 44. 
gular, como hace Elio Aristides ${ }^{22}$. Mención aparte merece el testimonio de Aquiles Tacio que en su novela Leucipa y Clitofonte justifica la interrupción de la llegada de tropas procedentes del Bajo Egipto por la aparición del Fénix en su tierra y la necesidad de rendirle culto:

[...] —iY cuál es esa ave que merece tal honor?, pregunté. ¿Y qué tumba es la que transporta? - Fénix es el nombre del ave. Es originaria de Etiopía y de tamaño como un pavo real, pero en la belleza de los colores es el pavo el que sale perdedor. Sus alas combinan oro y púrpura. Y se jacta de tener por amo al Sol y su cabeza da fe de ello, pues la corona una espléndida aureola circular, y el halo circular es el símbolo del Sol. Esta aureola es de un color carmín comparable al de las rosas, de muy hermosa vista, con un penacho de rayos que forma el orto de sus plumas. A los etíopes les corresponde el tiempo de su vida, a los egipcios su muerte, pues cuando muere (lo que ocurre muy de tarde en tarde), su cría la lleva hasta el Nilo, improvisándole su tumba. Excava con su pico una bola de la más aromática mirra y la ahueca en su parte central lo suficiente para la tumba del ave, ya que esta cavidad sirve de caja al cadáver. Mete y acomoda el ave en este féretro, ciega el agujero con una plasta de barro y vuela así cargada con su obra hasta el Nilo. La sigue un séquito de otros pájaros, como si fueran guardianes, pareciendo el ave un rey que sale de viaje, y no yerra su camino hacia Heliópolis, donde residirá el pájaro difunto. Se posa entonces en su lugar elevado, desde donde otea y acoge a los ministros del dios. Llega un sacerdote egipcio trayendo un libro del interior del santuario y comprueba con un grabado que se trata del ave verdadera. Ella se sabe objeto de tal desconfianza y pone a la vista las partes ocultas de su cuerpo, muestra el cadáver y es un experto orador de oraciones fúnebres. Los hijos de los sacerdotes de Helios reciben el ave muerta y la entierran. En fin, que en vida es etíope porque allí se nutrió, y al morir egipcia porque allí se enterró ${ }^{23}$.

La singularidad del texto ayuda a comprender mejor la evolución que va experimentando la concepción del mito del Fénix en el pensamiento simbólico romano. A pesar de que se mantienen muchos elementos presentados hasta el momento y que se recuperan otros de la tradición griega como el huevo de mirra, para no resultar demasiado repetitivo, nos centraremos únicamente en las novedades que introduce Aquiles Tacio.

En primer lugar, se consolida la idea del Fénix como ave solar, no solo por su consagración al Sol y su tratamiento y culto funerario realizado en Heliópolis, sino porque se erige como símbolo del propio sol a

22. ARISTEID. 2. 426.

23. TAC. AQ. 3. 24. 25. Traducción de M. Brioso Sánchez (Madrid, 1982). 
través de un elemento no aludido en los testimonios anteriores: la aureola circular de intenso color carmín que corona su cabeza.

Otro aspecto que parece introducirse ahora tiene que ver con la capacidad del ave de emitir cantos fúnebres, en este caso, no en los momentos previos a su muerte como veremos en fuentes posteriores, sino en el instante que precede a la entrega de los restos del antiguo Fénix a los sacerdotes de Heliópolis.

La imagen del Fénix coronado con una aureola circular de apariencia normalmente radial para resaltar su naturaleza solar será, precisamente, la que se emplee a la hora de materializar el ave en una iconografía de la época que tendrá en la numismática su principal soporte. Ejemplo de ello serán los áureos de Adriano del año 118 y del 121-122 d. C. o las monedas que emite el mismo en Alejandría entre el 137 y el 138 d. C. La idea que se quería transmitir con la presencia del Fénix en su iconografía tenía un doble significado. Por un lado, simbolizaba la eternidad que Adriano deseaba para su predecesor Trajano, presente también en las monedas con el apelativo divus. Por otra parte, trasladaba materialmente la idea propagandística de renovatio, es decir, del renacimiento del mundo que los ciudadanos romanos recibirían de su mandato en sintonía con esa concepción presente ya en el siglo anterior del Fénix como equivalente al concepto de Roma Aeterna y su constante renovación cíclica.

La figura del Fénix, bien en soledad o en combinación con otros elementos que incidían en su trascendencia simbólica de infinitud regenerada, como la bola del mundo situada a sus pies, la figura femenina de Aeternitas o del juvenil Aióv, su equivalente griego (símbolos todos de la renovación terrenal del nuevo mandato imperial); estará presente en las acuñaciones de cada uno de los emperadores que sucederán a Adriano a lo largo de esta segunda centuria (Antonino Pío, Marco Aurelio y Séptimo Severo). De igual modo, su importancia propagandística también incidirá en algunos emperadores de la siguiente, como así lo refleja un áureo de Treboriano Galo del 251-253 d. C. con un Fénix situado sobre un orbe sostenido, a su vez, por una Aeternitas acompañada de la leyenda Aeternitas Auggustorum, o un antoniniano de Emiliano del 253 d. C. con una imagen análoga ${ }^{24}$.

Si regresamos a las fuentes escritas, la transición del siglo II al III d. C. nos deja testimonios como el de Claudio Eliano ${ }^{25}$ en el que se insiste en la duración de 500 años del ciclo vital del Fénix. Como novedad se indica que el ave realizaría una serie de señales, no definidas en el texto, con las

24. LeCOCQ, 2009a, p. 84-91.

25. AIL. Anim. 6. 58. 
que ayudaría a los sacerdotes de Heliópolis a tener todo dispuesto para ejecutar los rituales de incineración de los restos de su anterior existencia. Sin embargo, para los objetivos de este trabajo, resulta más interesante el relato de Filóstrato:

Y el Fénix —prosiguió-, el ave que cada quinientos años visita Egipto vuela en la India por este tiempo; hay solo uno, emanado de los rayos del sol y brillante de oro; con talla y figura de águila, se asienta en un nido hecho de especias, junto a las fuentes del Nilo. Lo que los egipcios relatan sobre él, a saber, que va a Egipto, también lo confirman con su testimonio los indos, que cuentan como complemento a esta tradición que el Fénix, al consumirse en el nido, canta himnos funerales para sí mismo. Eso mismo afirmaban que hacen los cisnes los que han tenido suficiente habilidad para oírlos ${ }^{26}$.

La referencia a la India no debe ser considerada como un elemento distorsionante, puesto que la anterior localización en Arabia no remitía tampoco a una entidad espacial concreta, sino que constituía una alusión a los territorios más orientales del mundo conocido. Por otro lado, era bastante común en la época utilizar los términos India y Arabia como equivalentes.

Lo que sí resulta destacable es que Filóstrato atribuya a la tradición india el hecho de que, en los momentos previos a la muerte del Fénix, este emitiese una especie de canto fúnebre de manera semejante a como lo hacían los cisnes. Así, frente al testimonio de Aquiles Tacio que mencionaba indirectamente la capacidad cantora del Fénix, pero en el momento de la llegada del ave regenerada a Heliópolis y, tal vez, en relación a esas señales de aviso a los sacerdotes de las que hablaba Claudio Eliano; Filóstrato afirma abiertamente la emisión por parte del Fénix de cantos como señal premonitoria de su muerte.

El símil entre el Fénix y el cisne que plantea Filóstrato enlaza perfectamente con la tradición persa relativa al quaqnus analizada por Buendía ${ }^{27}$. Esta ave compartía ciertas características con el Fénix, pero no puede considerarse como equivalente, entre otras cosas, porque no era un animal que vivía en soledad y porque se caracterizaba, fundamentalmente, por su blancura inmaculada. Este último aspecto lo aproximaría más al cisne y, tal vez, explique la introducción de la capacidad cantora en el relato del Fénix en el momento en que es consciente de su muerte, como resultado de una eventual confusión entre la tradición de una y otra ave.

26. Fil. Apol. 3. 49. Traducción de A. Bernabé Pajares (Madrid, 1979).

27. Buendía, 2011. 
Centrándonos en las evidencias materiales, en esta transición del siglo II al III d. C. tenemos constatada también una representación mural procedente, en este caso, del ámbito cultural cristiano: la documentada en la Catacumba de Priscilia de Roma. La caracterización que se hace en esta pintura del Fénix contrasta en gran medida con la presente en la villa de Euxinus. Así, en el caso de la pintura cristiana vemos cómo el ave aparece en un contexto definido y entendible dentro de los elementos presentes en los relatos previamente comentados: el nido de especies aromáticas, tal vez, una combustión del Fénix y, lo más relevante, la presencia de esa aureola radial con la que se representaba también en las monedas de la época. Este último elemento se convertirá en una constante en los posteriores testimonios iconográficos del Fénix, como el documentado en el mosaico de la villa del Casale de Piazza Armerina (Sicilia) de la primera mitad del siglo Iv d. C. En este último se observa una composición idéntica a la anterior, aunque como una alegoría de las tierras egipcias o indias $y$, por lo tanto, sin una trascendencia simbólico-religiosa definida.

La presencia del Fénix en un contexto funerario de espiritualidad cristiana ayuda a comprender como la tradición grecolatina, incorporada ya desde los inicios del cristianismo en su simbología, como bien ejemplificaba Clemente, había evolucionado hasta formar parte de sus metáforas ultramundanas. Así, dentro de una lectura escatológica, necesaria por el contexto en el que nos situamos, parece que el mensaje de eternidad renovada que sugería el mito del Fénix y que había sido empleado por los emperadores romanos, es utilizado ahora también por el cristianismo. La diferencia radicará en que aquí se empleará como símbolo de la salvación eterna cristiana y como un paralelismo de la muerte y resurrección de Cristo que todo fiel cristiano aspiraba alcanzar y recrear. Se trataba, por lo tanto, de un mensaje de esperanza que envolvía de manera indirecta uno de los misterios más importantes del cristianismo y que sintonizaba a la perfección con las costumbres de camuflaje y clandestinidad que definirán a las comunidades cristianas en el contexto de persecución propio de este período.

Si nos movemos de la escatología cristiana a la tradicional romana, la epigrafía funeraria también se hace eco del mensaje de esperanza que el Fénix podía aportar al ser humano. Así, en un epitafio procedente de Ostia se podía leer:

[...] Si he tenido algún poder aquí, junto a los Manes, el ave Fénix vela por mí en el ara y se apresura a renacer junto conmigo ${ }^{28}$.

28. CIL XIV, 914=CLE, 1318. Traducción de C. Fernández Martínez (Madrid, 1998). 
A pesar de la ambigüedad del texto y de la ausencia de un contexto definido que nos permita datar con mayor precisión el momento del siglo III d. C. en que tendría lugar su realización, no parece posible atribuir la mención del Fénix al significado cristiano anteriormente expuesto. El motivo es sencillo. En un momento en el que cualquier manifestación cristiana debía mantenerse en el ámbito de la clandestinidad, no resulta factible una manifestación pública como la que constituye cualquier epitafio en el mundo funerario romano. Es necesario, de este modo, indagar otra posible trascendencia simbólica y, desde nuestro punto de vista, esta tan solo puede hallarse dentro de los postulados de la metempsicosis o de la doctrina de la transmigración de las almas.

Esta corriente filosófica de base órfico-pitagórica, moldeada y culminada por el pensamiento platónico, si bien no tendrá mucha repercusión en el conjunto de la ciudadanía romana, no por ello dejará de ser una opción escatológica presente en la misma a través de escritos de índole mitológica y filosófica ${ }^{29}$, pero también de realidades más mundanas como puede ser el caso de la epigrafía funeraria que estamos analizando.

Dentro de esta concepción, la alusión al Fénix es posible que remita a la confianza por parte del fallecido o del responsable de la erección del monumento de una vuelta a la vida terrenal a partir de la reencarnación de su alma en un nuevo ser mortal, como parte del ciclo de purificación que debería llevar a cabo toda alma humana con anterioridad a su ascenso definitivo a las esferas celestes de las que procedería.

Entre los siglos III y IV d. C., las fuentes textuales que abordan la problemática del Fénix tienen en Solino a su representante más notable ${ }^{30}$. El autor de la Collectanea rerum memorabilium parece recuperar la tradición del siglo I d. C. del mito, especialmente la versión proporcionada por Plinio. Así, lo demuestra la descripción morfológica del ave, la alusión a su visión en el año 36 d. C., frente al 34 d. C. sostenido por Tácito, la noticia de que Claudio expondría en público al animal en el 47 d. C., la referencia al gran año egipcio y, sobre todo, la duración del ciclo vital del Fénix de 540 años. Del mismo modo, lo que puede interpretarse como una novedad en el mito, como es esa alusión a Panquea (una isla imaginaria que se situaría en el corazón de Arabia) y que Solino la presenta como destino último del ave, parece tratarse de una confusión del autor a la hora de tratar la Pancaya citada por Plinio y que, al igual que él, situaba próxima a Heliópolis. La diferencia es que Plinio no confunde el lugar de

29. Caerols, 2011.

30. Sol. 33. 11. 
origen con el del destino de los restos mortales del Fénix, aspecto que es lo que parece estar sucediendo en el caso de Solino.

Alcanzado ya el siglo iv d. C., nos adentramos en una de las obras que con mayor exhaustividad trató el mito: De ave Phoenice atribuida a Lactancio. En este texto ya no encontraremos una alusión geográfica concreta que nos permita conocer el lugar de residencia del Fénix. Las referencias a la India o Arabia se mantienen para aludir al espacio de su nacimiento, pero el lugar en donde viviría sus 500 años es sustituido por un ámbito imaginario, «un bienaventurado territorio, más lejano que el remoto oriente, en donde se encuentra la puerta inmensa que se abre al cielo eterno ${ }^{31}$. Este estaría caracterizado por aquellos elementos que definían al mundo propio de la edad de oro griega y con la que Lactancio pretendía dar a entender que una criatura de esas características tan solo podía habitar en el Paraíso cristiano.

A continuación, se menciona, como no podía ser de otra manera, la singularidad del ave y su capacidad de renacer de su propia muerte. En lo relativo a los hechos protagonizados por el animal, las referencias a una especie de ritual de purificación que llevaría a cabo el Fénix con anterioridad a la construcción del nido que actuaría posteriormente como su sepulcro y que estaban presentes en Ovidio, vuelven a aparecer en Lactancio, pero ahora con una clara vinculación al rito bautismal cristiano de la época. Por otro lado, la capacidad cantora del ave insinuada por Aquiles Tacio y confirmada por Filóstrato, se recupera también, aunque con una mayor cantidad de detalles ${ }^{32}$, en el transcurso de unos rituales que efectuaría el Fénix cada amanecer de los días previos a su muerte y veneraría al Sol con su coronada cabeza.

A partir de aquí, Lactancio introduce una versión completamente original sobre el proceso de defunción y resurrección del ave que, a pesar de ello, estima que tendría lugar después del ya conocido ciclo de 500 años. Finalizados los cantos y los rituales de saludo al sol, el Fénix emprende su salida del Paraíso y "viene a nuestro mundo, donde reina la muerte, ${ }^{33}$. En concreto a las tierras fenicias en donde, en lo alto de una palmera de nombre phoenix, realidades que explicarían su denominación según el autor, construye un nido a partir de diversas especies aromáticas para dar paso a la siguiente escena:

Acomoda su cuerpo y da descanso a sus ya cansados miembros. Los rocía con su pico, al tiempo que se baña en los ricos jugos que

31. Lact. Phoenice. 1-3. Traducción propia.

32. LaCT. Phoenice 43-50.

33. Lact. Phoenice. 64. Traducción propia. 
extrae de la mezcla natural, envolviéndose entera a manera de quien cubre con un velo su cuerpo. Así se dispone a morir en sí misma. Entonces es cuando entrega su vida entre perfumes no teniendo más necesidad de cosa fastuosa. Se dice que de su cuerpo yerto emana calor que viene de la muerte misma. Este calor unido a los rayos rojos del sol prende en llamas que se exaltan por la luz del éter quemándolo todo y convirtiéndolo en cenizas. Estas se unen al líquido que descansa en el fondo mismo del nido formando una masa que es como el semen, del que surge otro ser vivo, sin huesos, similar al gusano que la tradición da color blanco, justamente, como la leche. Este gusano crece y al cabo de un cierto tiempo detiene su movimiento expansivo para replegarse como un huevo circular, similar a la manera como vemos en el campo a las orugas pegarse a las piedras con un cordón que mudará en mariposa. Así, el ave Fénix toma la misma figura que tuvo, renaciendo de sus quebrados despojos ${ }^{34}$.

Una vez alcanzado un cierto tamaño, iniciaría el embalsamiento conocido de los restos mortales de los que procede para iniciar su peregrinaje a Heliópolis con el objetivo de rendir culto a su anterior existencia. Descritas estas acciones, Lactancio nos ofrece la caracterización más completa del Fénix realizada hasta el momento ${ }^{35}$ y continúa el relato aludiendo a hechos que tienen lugar en Heliópolis y que son protagonizados por sus sacerdotes, como el grabado en mármol de su llegada o el peregrinaje de aves que la acompañan a tierras egipcias. Para finalizar, Lactancio, vuelve a enlazar el mito del Fénix con el cristianismo en una alegoría evidente de la triple naturaleza de Cristo y del Dios cristiano ${ }^{36}$.

En el fondo, el texto de Lactancio representa la culminación de un proceso que habían iniciado otros intelectuales cristianos anteriores, como el ya mencionado Clemente ${ }^{37}$, otros como Tertuliano ${ }^{38}$ u Orígenes ${ }^{39}$ y que seguirá presente en figuras como Ambrosio ${ }^{40}$ o Agustín ${ }^{41}$. En todos ellos, el Fénix actuará como un ejemplo o un paralelismo de la veracidad de la resurrección y la reencarnación llevada a cabo por Cristo en la tierra. Con el tiempo, también simbolizará la inviolata virginitas de la Virgen María

34. Lact. Phoenice. 89-108. Traducción propia.

35. LACT. Phoenice. 125-150.

36. LaCt. Phoenice. 169-170.

37. Clem. Ep. Cor. 25.

38. Tert. Res. 13.

39. ORIG. Cels. 4. 98.

40. Ambr. Exc. Sat. 2. 59.

41. August. Anim. 4. 20. 
de manera semejante a lo sucedido en otro mito de tradición "pagana" como el de las yeguas lusitanas fecundadas por el viento ${ }^{42}$.

Tras el análisis de Lactancio, llegamos así a una figura íntimamente relacionada por parte de la historiografía y la lingüistica a su obra: Claudiano y su Phoenix. A pesar de las cronologías dispares que se dan para la existencia de uno y otro, lo cierto es que las dudas acerca de si Lactancio pudo haber imitado la obra de Claudiano, si, por el contrario, es este quien bebió de Lactancio o si ambos autores, en realidad, realizaron una obra independiente basada en una fuente común, han sido cuestiones debatidas constantemente en las últimas décadas ${ }^{43}$.

$\mathrm{Al}$ igual que Lactancio, Claudiano nos presenta el espacio habitacional del Fénix con tintes paradisíacos y, desde luego, al margen de cualquier actividad humana o realidad terrenal. La descripción física del Fénix también concuerda bastante, a excepción de las tonalidades purpúreas que asocia a sus patas y las azules y doradas que atribuye a sus alas. Lo mismo se puede decir de los preparativos para la muerte del animal consistentes en la construcción del nido con especies aromáticas y los rituales de veneración al sol entre los que incluye un canto. En esta ocasión, Claudiano justifica la realización de este último como el medio a partir del cual el Fénix recibiría del Sol las fuerzas y el fuego que le permitirían arder y renacer a continuación de sus cenizas. Quizás la divergencia más importante en este punto del relato con respecto a Lactancio, sea la duración de vida del Fénix que Claudiano sitúa en unos 1.000 años y la omisión que realiza del gusano que se transformaría en un nuevo Fénix, una imagen que se simplifica y se presenta de la siguiente forma:

[...] Ya se abrasa por su propia voluntad para regresar de nuevo, y se alegra de morir, impaciente por su nacimiento. Con los dardos divinos arde el montón oloroso de fronda y consume a la vieja ave; la luna retiene estupefacta sus resplandecientes novillos y el cielo no agita sus perezosos astros mientras la pira lo crea; Naturaleza se preocupa con inquietud para no perder al ave eterna y le advierte a sus fieles llamas que le devuelvan la gloria inmortal del mundo. Enseguida un aflujo de vigor circula por sus miembros esparcidos y una sangre renovada inunda sus venas. Sin nadie que las mueva, las cenizas destinadas a vivir comienzan a agitase y a cubrir de plumas el informe rescoldo. El mismo que había sido padre, sale ahora hijo y, nuevo ser, se sucede a

42. Freán CAmpo, 2016.

43. Callejas Berdones, 1986-1987. 
sí mismo. El fuego separa en medio los límites de las dos vidas con una tenue frontera ${ }^{44}$.

Acto seguido, Claudiano ilustra el viaje del Fénix a Heliópolis seguido de un cortejo de aves diversas y los rituales que tendrían lugar en la ciudad, de una manera muy similar a la expuesta por Lactancio ${ }^{45}$. Las similitudes entre ambos relatos son evidentes y marcarán, sin duda, el devenir del mito a lo largo de la Edad Media. La principal diferencia radica en que Lactancio muestra un esfuerzo manifiesto por adecuar un mito "pagano" a la simbología cristiana. Claudiano, por su parte, tan solo expone un mito que es tratado de una forma poética y ajena a cualquier trascendencia simbólica ${ }^{46}$, como así ejemplifica el final de su obra ${ }^{47}$, muy distinto del mensaje cristiano que transmitía Lactancio.

Con Claudiano nos adentramos en el siglo v d. C., un período de grandes cambios políticos, económicos, sociales y culturales, pero de continuidades en lo que se refiere a la concepción del ave Fénix. Este mantendrá su camino en el imaginario de los diferentes reinos derivados del Imperio por ese doble sentido que, en parte, anticiparon De ave Phoenice y Phoenix: uno en el que se empleará como recurso simbólico para explicar determinados misterios del cristianismo y otro centrado en el ámbito de la erudición y de la estética poética.

\section{CONClusiones}

Cuando en el siglo vil d. C. un obispo de Sevilla reciba el encargo de almacenar, sistematizar y condensar todo el conocimiento heredado de la antigüedad a través de sus Etimologías, decidirá escribir las siguientes palabras a la hora de explicar el origen y el significado de la palabra Fénix:

El Fénix es un ave de la Arabia, llamada así por el color rojo que tiene o porque es singular y única, y así es como la llaman los árabes. Vive quinientos y más años, y cuando se ve anciana, reuniendo ramitas de plantas aromáticas, forma una pira, y puesta sobre ella, mirando los rayos del sol, fomenta el fuego con el movimiento de sus alas; se consume y sale viva de nuevo de sus cenizas ${ }^{48}$.

44. Claud. Phoenix. 57-71. Traducción de M. Castillo Bejarano (Madrid, 1993).

45. Claud. Phoenix. 72-100.

46. Callejas Berdones, 1986-1987, p. 120.

47. Claud. Phoenix. 101-110.

48. Isid. Etym. 12. 7. 22. Traducción de L. Cortés y Góngora (Madrid, 1951). 
Esta será la imagen que perdurará, grosso modo, hasta nuestros días y el resultado, como vimos, de la evolución de un mito nacido en Egipto, alterado por la tradición griega, asimilado por la romana y redefinido por el cristianismo.

A lo largo de esta evolución hemos podido observar cómo un ave caracterizado por poseer tonalidades rojizas y doradas fue envolviendo su plumaje con pigmentos cada vez más diversos y exóticos, pero entre los que fue ganando terreno ese púrpura con el que se asociaba en la antigüedad a las tierras fenicias. De igual modo, de una morfología aparentemente común y próxima al de las águilas, el Fénix fue adoptando componentes nuevos y diferenciadores como las crestas y, especialmente, la aureola radial que envolverá su cabeza.

Sus acciones también fueron experimentando modificaciones. Del simple peregrinaje que realizaba cíclicamente de su Arabia natal a Heliópolis portando los restos de su anterior existencia, fuimos observando cómo se iban definiendo un mayor número de detalles relacionados con la duración de su vida, su alimentación, su proceso de regeneración, los actos que llevaba a cabo con anterioridad y posterioridad a su peregrinación, hasta conocer, incluso, aspectos del paisaje y de los componentes que formaban parte de su hábitat.

Pero, sin duda, los cambios más relevantes tuvieron que ver con el significado último del mito. Así, el ave Fénix había irrumpido en el pensamiento simbólico romano como una creencia ajena a su religiosidad y, por lo tanto, como una fuente de estudio o una referencia más con la que caracterizar a las poblaciones y el territorio de una determinada región del orbe, en este caso, la de Arabia. Posteriormente, la trascendencia simbólica de su capacidad regeneradora fue empleada por parte de la propaganda imperial como un símbolo de eterna y renovada perpetuidad. Esa misma concepción sirvió, al mismo tiempo, para que el Fénix se fuera abriendo paso en la escatología romana, tanto en la cristiana como en la tradicional, sintonizando, en este último caso, con los postulados sostenidos por la doctrina de la metempsicosis o de la transmigración de las almas. Con todo, el significado con el que el ave culminará la antigüedad será con uno estrechamente vinculado a la simbología cristiana oficial y dominante desde el siglo iv d. C.: la representación análoga de la resurrección llevada a cabo en la tierra por Cristo y una muestra de cómo Dios haría patente a los hombres los misterios de la "fe verdadera". De este modo, una creación que había nacido como una manifestación de una religión propia de un espacio de naturaleza desértica regresaba a otra de idéntica condición, pero dotada de un significado totalmente diferente. 
Más de 2000 años después de que Heródoto recogiera en sus escritos aquello que había escuchado y visto en Heliópolis, Quevedo definía en tono irónico al pelícano y al Fénix como:

Aves que la lengua dice,

pero que nunca las prueba;

bien sé que desmiento a muchos,

que muy crédulos las cuentan,

mas si ellos citan a Plinio,

yo citaré a las despensas.

Si las afirman los libros,

las contradicen las muelas ${ }^{49}$.

A lo largo de este trabajo hemos intentado sintetizar aquellos testimonios de la antigüedad que trataron el mito del Fénix con el objetivo de aproximarnos a la concepción que los romanos tendrían de esta criatura y como esta evolucionaría con el paso del tiempo. En buena parte de ellos hemos podido comprobar cómo esa dosis de escepticismo quevedesco estaba muy presente y, sin embargo y como advertíamos al inicio del artículo, el mito del Fénix pervive aún en nuestros días.

¿Cómo es posible? Seguramente tenga algo que ver el hecho de que el Fénix represente una realidad simbólica versátil y adaptable a cualquier sociedad o contexto cultural, como consecuencia de la universalidad que desprende su trascendencia conceptual: la posibilidad de enmendar o eliminar parte de nuestro pasado, la de superar el trance existencial de la muerte y la de alcanzar así la siempre anhelada eternidad. De esta forma, se podría decir que, más que un mito relacionado con una criatura fantástica, el ave Fénix representa como ningún otro el reflejo de una aspiración humana universal de la que los romanos no se mantuvieron, ni mucho menos, al margen.

\section{Bibliografía}

Anglada Anfruns, A.: El mito del Ave Fénix. Barcelona, 1983.

Buendía, P.: "Acerca del Ave Fénix en las tradiciones islámicas", AlQantara, 32 (1), 2011, p. 7-26.

Caerols, J. J.: "La doctrina de la transmigración de las almas en Roma", en Bernabé, A.; Kahle, M. y Santamaría, M. A. (eds.): Reencarnación. La

49. Quev. El Parnaso Español. 1. 11-18. 
transmigración de las almas entre oriente y occidente. Madrid, 2011, p. 351-383.

Callejas Berdones, M. T.: "Confrontación del "De Ave Phoenice" de Lactancio y el "Phoenix" de Claudiano", CFC(L), 20, 1986-1987, pp. 113-120.

Diego BaRRAdo, L.: "La representación del ave fénix como imagen de la Renovatio de la Roma altomedieval", Anales de Historia del Arte, Volumen Extraordinario, 2010, pp. 171-185.

FREÁN CAMPO, A.: "El mito de las yeguas lusitanas: una realidad simbólica liminar, Forma Breve, 13, 2016, p. 357-373.

Gosserez, L.: "Le phénix coloré, d'Herodote à Ambroise de Milan", BAGB, 1, 2007, pp. 94-117.

GualandRI, I.: "Un papiro milanese, Lattanzio, Claudiano e il mito della fenice", Rend. Acc. Nat. Lin., 29, 1974, pp. 293-311.

Harrison, P.: “Bird of Paradise: Phoenix Redivivus", Isis, 51 (2), 1960, pp. 173-180.

Hart, G.: Mitos Egipcios. Madrid, 1994.

Hubaux, J., Leroy, M.: Le Mythe du Phénix dans les littératures grecque et latine. Liège, 1939.

LeCocQ, F.: "L'empereur romain et le phénix", en Fabrizio-Costa, S. (ed.): Phénix: mythe(s) et signe(s). Bern, 2001, pp. 27-56.

LeCOCQ, F.: "Les sources égyptiennes du mythe du phénix", en LeCocQ, F. (ed.): L'Égypte à Rome. Caen, 2008, pp. 211-266.

LECOCQ, F.: "L'iconographie du phénix à Rome", en FÉvrier, C. (ed.): L'image de l'animal dans l'Antiquité. Caen, 2009a, pp. 73-106.

LecocQ, F.: "L'oeuf du phénix. Myrrhe, encens et cannelle dans le mythe du phénix", Schedae, 17 (2), 2009b, pp. 107-130.

Pellicer, J.: El fenix y su historia natural escrita en veinte y dos exercitaciones, diatribes o capitulos. Madrid, 1630.

RAPISARDA, E.: Il carme "De ave phoenice" di Lattanzio. Catania, 1946.

Siciliano, R.: "Origine del mito della fenice: dall'Egitto al mondo greco", AFLB, 37-38, 1994-1995, pp. 309-318.

Van Den Broek, R.: The Myth of the Phoenix According to Classical and Early Christian Traditions. Leiden, 1972.

Walla, M.: Der Vogel Phoenix in der antiken Literatur und der Dichtung des Laktanz. Wien, 1969. 